Pacific Journal of Mathematic 


\section{A NEW APPROACH TO THE KREIN-MILMAN THEOREM}

\section{J. Martinez Maurica and C. Perez Garcia}

In this paper we give a new definition of extreme points for which we get a generalization of the Krein-Milman theorem within the general context of locally convex spaces over valued fields.

Some generalizations of the theorem of Krein-Milman were developed in the seventies in order to include other types of topological vector spaces apart from the usual ones (e.g. Kalton's papers within the context of locally $p$-convex spaces). However, A. F. Monna says in 1974 that no way is known to attack problems such as the Krein-Milman theorem in ultrametric analysis (i.e. when the real or complex field is substituted for another valued field).

In order to give a theorem of Krein-Milman which includes the case of locally $p$-convex spaces $(p \in(0,1])$ and the ultrametric case, we propose a new definition of extreme points. The latter definition agrees with the usual one in case the ground field is $R$ or $C$ and it allows us to give a non-archimedean Krein-Milman theorem.

We are going to consider vector spaces $E$ over any complete non-trivially valued field $K$. For $K=R, C$, and $p \in(0,1]$ we say that $A \subset E$ is $p$-convex if $\lambda A+\mu A \subset A$ for all $\lambda, \mu \geq 0$ such that $\lambda^{p}+\mu^{p}=1$. For a non-archimedean valued field $K$ two different kinds of convex sets will be considered: $A \subset E$ is said to be $M$-convex (convex à la Monna) if $\lambda A+\mu A+\nu A \subset A$ for all $\lambda, \mu, \nu \in K$ such that $|\lambda|,|\mu|,|\nu| \leq 1$ and $\lambda+\mu+\nu=1$; and for $a \in E$, the set $A \subset E$ is said to be $a$-convex if $A$ is $M$-convex and $a \in A$. More details over these kinds of convex sets we will use in the sequel are in [3] (for $p$-convex sets) and [5] (for the non-archimedean case).

In the sequel we will use the term "convex" to indicate any of the different kinds of convex sets; also $E_{c}(A)$ stands for the corresponding convex hull of $A$.

1. Semiconvexity. Extreme points. The following definition is very close to the weak-convexity of Monna ([5] p. 28). 
Definition 1. Let $E$ be a vector space over a valued field $K$. A subset $A$ of $E$ is said to be semiconvex if $\lambda A+(1-\lambda) A \subset A$ for every $\lambda$ of $K$ satisfying $|\lambda|<1$.

Notice that if $K=R, C$ every semiconvex set is 1-convex and if $K$ is non-archimedean every $M$-convex set and every $a$-convex set are semiconvex.

Definition 2. Let $E$ be a vector space over a valued field $K$ and $A$ a subset of $E$. A non-empty part $S$ of $A$ is said to be an extreme set of $A$ if the following properties are verified:

(i) $S$ is semiconvex.

(ii) If $x_{1}, \ldots, x_{n} \in A$ and $E_{c}\left\{x_{1}, \ldots, x_{n}\right\} \cap S \neq \varnothing$, then there exists an index $i \in\{1, \ldots, n\}$ such that $x_{i} \in S$.

It is easy to verify that if $A$ is convex, then the property (ii) is equivalent to $A-S$ is convex.

Definition 3. Let $E$ be a vector space over $K$ and $A$ a subset of $E$. A point $x \in A$ is said to be an extreme point of $A$ if it belongs to some minimal element of

$$
E_{A}=\{S \subset A \mid S \text { is an extreme set of } A\} .
$$

Next, we prove that if $K=R, C$ this definition gives the same extreme points as the usual ones for every $p$-convex compact set $A$ of a separated locally $p$-convex space. For that, we denote by $E_{p}(A)$ the set of $p$-extreme points of $A$ according to the definition of Kalton [4]. (Notice that this definition is slightly different from the corresponding definition of Jarchow [3], however they agree for closed $p$-convex sets). Also $F_{p}(A)$ indicates the set of extreme points of $A$ corresponding to our Definition 3 for $p$-convex sets.

THEOREM 1. Let $E$ be a Hausdorff locally p-convex space over $K=R, C$ and let $p \in(0,1]$. If $A$ is a non-empty compact $p$-convex set of $E$, then:

(1) Every minimal element of $E_{A}$ consists of one point.

(2) $F_{p}(A)=E_{p}(A)$.

Proof. (1) Let $S$ be a minimal element of $E_{A}$ and suppose $x, y$ are different points of $S$. As $\bar{S}$ is semiconvex and closed, $\lambda \bar{S}+(1-\lambda) \bar{S} \subset \bar{S}$ for every $\lambda \in K$ such that $|\lambda| \leq 1$. Consequently $2 y-x \in \bar{S}$; and also for $n=1,2 \ldots z_{n}=(n+1) y-n x \in \bar{S}$. So the sequence $\left(z_{n}\right) \subset \bar{S}$ verifies $\lim \left(z_{n} / n\right)=y-x \neq 0$ and $\bar{S}$ is not bounded. 
(2) This follows from (1) and the fact that $x \in E_{p}(A)$ if and only if $A-\{x\}$ is $p$-convex (see [2] p. 96 for $p=1$ and [4] for any $p$ ).

2. Non-Archimedean extreme points. Throughout the rest of the paper, $E$ will indicate a topological vector space over a field $K$, endowed with a non-trivial non-archimedean valuation. We are going to restrict ourselves to the case of $K$ local (i.e. locally compact) (otherwise there do not exist any compact convex set with more than one point [5] p. 40).

Theorems in this section are proved for 0-convex sets; however with minor changes they remain true for the other kinds of convexities over $E$.

THEOREM 2. Let $E$ be a topological vector space over $K$ and assume that $E^{\prime}$ separates points of $E$. Then, every convex and compact subset $A$ of $E$ has extreme points.

Before proving the theorem we need the following lemma:

LeMMA 1. Let $E$ be a topological vector space over $K$ and let $A, B$ be convex sets in $E$ with $B \subset A$. If the interior of $B$ in $A$ is non-empty, then $B$ is clopen in $A$.

Proof. Take $x_{0} \in B$ such that $B$ is a neighborhood of $x_{0}$ in $A$. Now, if $x \in B$, then $B=B-x_{0}+x$; hence $B$ is a neighborhood of $x$ in $A$ and $B$ is open in $A$. Also, if $y \in A-B$, then $B \cap(y+B)=\varnothing$ and consequently $A-B$ is open in $A$.

Proof (of Theorem 2). Let $A$ be with more than one point and define $C E_{A}=\{S \subset A \mid S$ is a closed extreme set of $A\}$.

$C E_{A}$ is non-empty and a standard application of Zorn's lemma shows that $C E_{A}$ has some minimal element.

Let $S_{0}$ be one such minimal element. First we prove that $S_{0} \neq A$.

For that, choose $f \in E^{\prime}$ such that $f(A)$ is not reduced to be a single point and define

$$
S_{f}=\left\{s \in A|| f(s)\left|=\sup _{x \in A}\right| f(x) \mid\right\} .
$$

It is easy to verify that $S_{f} \in C E_{A}$ and that $S_{f} \neq A$. Then, $S_{0} \neq A$.

Let $S \in E_{A}$ such that $S \subset S_{0}$. Applying Lemma 1 to $A$ and $A-S$, we deduce that $S$ is closed in $E$. Thus $S_{0}=S$ and $S_{0}$ is a minimal element of $E_{A}$.

COROLlaRY 1. Under the assumptions of the Theorem 2, every closed extreme subset of $A$ contains extreme points of $A$. 
If $A \subset E$ we will denote by $\operatorname{Ext}(A)$ the set of extreme points of $A$. In the following theorem we use the terminology of [1].

Theorem 3 (Non-archimedean Krein-Milman theorem). Let $E$ be a Hausdorff locally convex space over $K$. If $A$ is a non-empty convex compact set of $E$, then $A=\bar{E}_{c}(\operatorname{Ext}(A))$.

Proof. For $x_{0} \in A-\bar{E}_{c}(\operatorname{Ext}(A))$, let $H$ be a closed hyperplane which separates $x_{0}$ and $\bar{E}_{c}(\operatorname{Ext}(A))$, and let $f(x)=\alpha$ an equation of $H\left(f \in E^{\prime}\right)$. As $S_{f} \in C E_{A}$ (see the preceding theorem), we can choose $x \in \operatorname{Ext}(A) \cap S_{f}$. Also, $\bar{E}_{c}(\operatorname{Ext}(A))$ is in one side of $H$, so $|f(y)|<|\alpha|$ for every $y \in$ $\bar{E}_{c}(\operatorname{Ext}(A))$. It follows that $|f(a)| \leq|f(x)|<|\alpha|$ for every $a \in A$.

Thus, $A$ and $\bar{E}_{c}(\operatorname{Ext}(A))$ are in the same side of $H$ and, therefore, $x_{0} \notin A$.

The main difference between the real or complex case and the non-archimedean case is contained in the following theorem.

THeOREM 4. Let $E$ be a Hausdorff topological vector space over $K$ and let $A$ be a convex set in $E$ with more than one point. Then, every extreme set of $A$ cannot be reduced to a single point.

Proof. Suppose $A$ to be absorbing (otherwise replace $E$ by the linear hull of $A$ ).

First suppose that the interior of $A$ is non-empty (i.e. $A$ is clopen). If $S$ is an extreme set of $A$ with only one point, then $A-S$ is an open convex set in $A$. Thus (Lemma 1) $A-S$ is clopen in $A$ and, consequently, $S$ is open.

Now assume $A$ to be bounded and let $\tau_{p}$ be the topology on $E$ defined by the Minkowski's functional of $A$. If $\tau$ is the original topology in $E$ we have $\tau \leq \tau_{p}$ and the interior of $A$ with respect to $\tau_{p}$ is non-empty. Now apply the first result of this proof.

Finally, let $A$ be any set in the hypotheses of the theorem. If $S=\{x\}$ is an extreme set of $A$, take $y \in A-\{0\}$ such that $x \in\{\lambda y|| \lambda \mid \leq 1\}=$ $A_{y}$. Therefore, $S$ ought to be an extreme set of the bounded convex set $A_{y}$.

3. An expression of the extreme points. First we are going to consider the case of 0-convex compact sets. Such a subset $A$ of a Hausdorff topological vector space $E$ can be expressed in the following way:

$$
A=\left\{\sum_{i \in I} x_{i} e_{i}|| x_{i} \mid \leq 1\right\}
$$


where $\left(e_{i}\right)_{i \in I}$ is a topologically independent family of elements of $A$. The expression of each element of $A$ as a sum $\sum_{i \in I} x_{i} e_{i}$ is unique, and the convergence of the sums is in the sense of the Cauchy's filter ([1] p. 152). If $x=\sum_{i \in I} x_{i} e_{i}$ we put $\left\langle x, e_{i}\right\rangle=x_{i}$.

We denote $\operatorname{Ext}_{0}(A)$ the set of the extreme points of $A$ for the 0 -convexity. Also, $p_{A}$ denotes the Minkowski's functional of $A$ in the linear hull of $A$.

THEOREM 5. Let E be a Hausdorff topological vector space over $K$ and let $A$ be a 0-convex compact set of $E$. If $\left(e_{i}\right)_{i \in I}$ is a family of points of $A$ satisfying (1), then the following properties for a point $x \in A$ are equivalent:

(i) $x \in \operatorname{Ext}_{0}(A)$.

(ii) $\sup _{i \in I}\left|\left\langle x, e_{i}\right\rangle\right|=1$.

(iii) There exists $i_{0} \in I$ such that $\left\langle x, e_{i_{0}}\right\rangle \mid=1$.

(iv) $p_{A}(x)=1$.

Proof. For $i \in I$, consider

$$
D_{i}=\left\{x \in A||\left\langle x, e_{i}\right\rangle \mid=1\right\} .
$$

$D_{i}$ is a 0 -extreme set of $A$. Now we wish to prove that $D_{i}$ is minimal. Otherwise, consider $T$ to be a proper subset of $D_{i}$ which is a 0 -extreme set of $A$. Take $x \in D_{i}-T$ and define $y \in A$ in the way $\left\langle y, e_{j}\right\rangle=x_{j}$ for $j \neq i$ and $\left\langle y, e_{i}\right\rangle=0$. Obviously $y \in A-T$, and being $A-T 0$-convex, then $\left\langle x, e_{i}\right\rangle^{-1}(x-y)=e_{i} \in A-T$. Pick $t \in T$ and define $z \in A-T$ in the way $\left\langle z, e_{j}\right\rangle=t_{j}$ for $j \neq i$ and $\left\langle z, e_{i}\right\rangle=0$. Finally, we have $t=\left\langle t, e_{i}\right\rangle e_{i}$ $+z$ which contradicts the assumption that $A-T$ is 0 -convex. This proves (iii) $\Rightarrow$ (i).

The equivalence (ii) $\Leftrightarrow$ (iii) is obvious because the valuation over $K$ is discrete.

For the equivalence (ii) $\Leftrightarrow$ (iv), it is straightforward to verify that for a point $x \in A, p_{A}(x)=\sup _{i \in I}\left|\left\langle x, e_{i}\right\rangle\right|$.

For (i) $\Rightarrow$ (ii), consider an $x \in A$ such that $\sup _{i \in I}\left|\left\langle x, e_{i}\right\rangle\right|<1$. Choose $\mu \in K$ with $|\mu|>1$ such that $\mu x \in A$. If $S$ is a proper 0 -extreme set of $A$ which contains $x$, then $\mu x \in S$. Also, $0=\lambda \mu x+(1-\lambda) x \in S$ (with $\lambda=-1 /(\mu-1)$ ) which contradicts that $A-S$ is 0 -convex. Hence, $x \notin$ $\operatorname{Ext}_{0}(A)$.

REMARKS. (1) The latter theorem holds for a compact $a$-convex set $A$. In fact, under the conditions of the Theorem 5 , the following properties are equivalent: (i) $x \in \operatorname{Ext}_{a}(A)$ (ii) $\sup _{i \in I}\left|\left\langle x-a, e_{i}\right\rangle\right|=1$ (iii) There exists $i_{0} \in I$ such that $\left|\left\langle x-a, e_{i_{0}}\right\rangle\right|=1$ (iv) $p_{A-a}(x-a)=1$ where 
$\operatorname{Ext}_{a}(A)$ indicates the set of $a$-extreme points of $A$ and $\left(e_{i}\right)_{i \in I}$ satisfies (1) for the 0-convex set $A-a$.

(2) However, if we consider $M$-convex sets, the result we get is trivial. If we put $\operatorname{Ext}_{M}(A)$ to indicate the set of $M$-extreme points of an $M$-convex set $A$, and with the assumptions on $E$ of Theorem 5 we have:

\section{Corollary 2. $\operatorname{Ext}_{M}(A)=A$.}

Proof. It follows from the fact that $\left\{x \in A\left|\left\langle x-a, e_{i}\right\rangle\right|=1\right\}$ is a minimal element of $E_{A}$ (for this convexity) for all $a \in A, i \in I$.

(3) Our Theorem 5 is quite similar to the Theorem 2 of Kalton's paper [4], which establishes that every point of a compact $p$-convex $(0<p<1)$ subset $A$ of a Hausdorff topological vector space $E$ can be expressed in the way $x=\sum a_{n} x_{n}$ with $a_{n} \geq 0, \sum a_{n}^{p}=1$ and $\left(x_{n}\right)$ being a sequence of distinct $p$-extreme points of $A$.

\section{REFERENCES}

[1] J. P. Carpentier, Seminormes et ensembles convexes dans un espace vectoriel sur un corps valué ultramétrique, Séminaire Choquet, (1964-1965), 91-158.

[2] G. Choquet, Lectures on Analysis. Vol. II, W. A. Benjamin (1969).

[3] M. Jarchow, Locally convex spaces, Teubner, Stuttgart (1981).

[4] N. J. Kalton, Compact p-convex sets, Quart. J. Math. Oxford Ser. (2). 28. no. 111, (1977), 301-308.

[5] A. F. Monna, Analyse non-archimedienne, Springer-Verlag, Berlin (1970).

[6] __ Rapport sur la théorie des espaces linéaires topologiques sur un corps valué non-archimedien, Bull. Soc. Math. France, Mémoire, No. 39-40, (1974), 255-278.

Received April 4, 1984.

SCIENTIFIC UNIVERSITY OF SANTANDER

SANTANDER, SPAIN 


\section{PACIFIC JOURNAL OF MATHEMATICS EDITORS}

\author{
V. S. VARADARAJAN (Managing Editor) \\ University of California \\ Los Angeles, CA 90024 \\ Charles R. DePrima \\ California Institute of Technology \\ Pasadena, CA 91125 \\ R. FINN \\ Stanford University \\ Stanford, CA 94305
}

\author{
HeRmanN FlaschKa \\ University of Arizona \\ Tucson, AZ 857.21
}

RAMESH A. GANGOLli

University of Washington

Seattle, WA 98195

ROBION KIRBY

University of California

Berkeley, CA 94720
C. C. MOORE

University of California

Berkeley, CA 94720

H. SAMELSON

Stanford University

Stanford, CA 94305

HAROLD STARK

University of California, San Diego

La Jolla, CA 92093

\section{ASSOCIATE EDITORS}
R. ARENS
E. F. BECKENBACH
B. H. NeumanN
F. WOLF
K. YoSHIDA
(1906-1982)

\section{SUPPORTING INSTITUTIONS}

\begin{abstract}
UNIVERSITY OF ARIZONA
UNIVERSITY OF BRITISH COLUMBIA

CALIFORNIA INSTITUTE OF TECHNOLOGY

UNIVERSITY OF CALIFORNIA

MONTANA STATE UNIVERSITY

UNIVERSITY OF NEVADA, RENO

NEW MEXICO STATE UNIVERSITY

OREGON STATE UNIVERSITY
\end{abstract}

\author{
UNIVERSITY OF OREGON \\ UNIVERSITY OF SOUTHERN CALIFORNIA \\ STANFORD UNIVERSITY \\ UNIVERSITY OF HAWAII \\ UNIVERSITY OF TOKYO \\ UNIVERSITY OF UTAH \\ WASHINGTON STATE UNIVERSITY \\ UNIVERSITY OF WASHINGTON
}

The Supporting Institutions listed above contribute to the cost of publication of this Journal, but they are not owners or publishers and have no responsibility for its content or policies.

Mathematical papers intended for publication in the Pacific Journal of Mathematics should be in typed form or offset-reproduced (not dittoed), double spaced with large margins. Please do not use built up fractions in the text of the manuscript. However, you may use them in the displayed equations. Underline Greek letters in red, German in green, and script in blue. The first paragraph must be capable of being used separately as a synopsis of the entire paper. In particular it should contain no bibliographic references. Please propose a heading for the odd numbered pages of less than 35 characters. Manuscripts, in triplicate, may be sent to any one of the editors. Please classify according to the scheme of Math. Reviews, Index to Vol. 39. Supply name and address of author to whom proofs should be sent. All other communications should be addressed to the managing editor, or Elaine Barth, University of California, Los Angeles, California 90024.

There are page-charges associated with articles appearing in the Pacific Journal of Mathematics. These charges are expected to be paid by the author's University, Government Agency or Company. If the author or authors do not have access to such Institutional support these charges are waived. Single authors will receive 50 free reprints; joint authors will receive a total of 100 free reprints. Additional copies may be obtained at cost in multiples of 50 .

The Pacific Journal of Mathematics is issued monthly as of January 1966. Regular subscription rate: $\$ 190.00$ a year (5 Vols., 10 issues). Special rate: $\$ 66.00$ a year to individual members of supporting institutions.

Subscriptions, orders for numbers issued in the last three calendar years, and changes of address should be sent to Pacific Journal of Mathematics, P.O. Box 969, Carmel Valley, CA 93924, U.S.A. Old back numbers obtainable from Kraus Periodicals Co., Route 100, Millwood, NY 10546.

The Pacific Journal of Mathematics at P.O. Box 969, Carmel Valley, CA 93924 (ISSN 0030-8730) publishes 5 volumes per year. Application to mail at Second-class postage rates is pending at Carmel Valley, California, and additional mailing offices. Postmaster: Send address changes to Pacific Journal of Mathematics, P.O. Box 969, Carmel Valley, CA 93924.

PUBLISHED BY PACIFIC JOURNAL OF MATHEMATICS, A NON-PROFIT CORPORATION

Copyright $\odot 1985$ by Pacific Journal of Mathematics 


\section{Pacific Journal of Mathematics}

Vol. 120, No. $2 \quad$ October, 1985

Philip Marshall Anselone and Mike Treuden, Regular operator

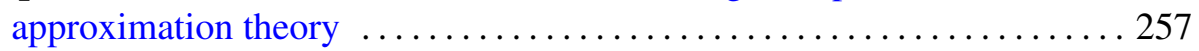

Giuseppe Baccella, Semiprime $\aleph-Q F 3$ rings $\ldots \ldots \ldots \ldots \ldots \ldots \ldots \ldots . \ldots \ldots$

Earl Robert Berkson and Thomas Alastair Gillespie, The generalized M.

Riesz theorem and transference $\ldots \ldots \ldots \ldots \ldots \ldots \ldots \ldots . \ldots 279$

Joachim Boidol, A Galois-correspondence for general locally compact

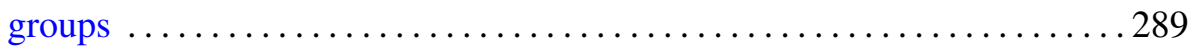

Joseph Eugene D'Atri, Josef Dorfmeister and Yan Da Zhao, The isotropy

representation for homogeneous Siegel domains ............... 295

C. Debiève, On Banach spaces having a Radon-Nikodým dual

Michael Aaron Freedman, Existence of strong solutions to singular

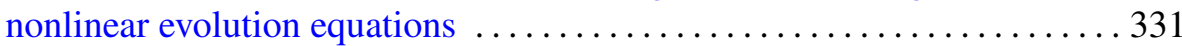

Francisco Jose Freniche, Grothendieck locally convex spaces of continuous

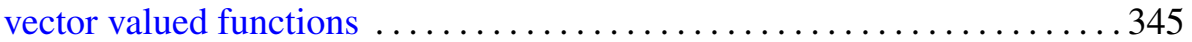

Hans-Peter Künzi and Peter Fletcher, Extension properties induced by complete quasi-uniformities . ............................ 357

Takaŝi Kusano, Charles Andrew Swanson and Hiroyuki Usami, Pairs of

positive solutions of quasilinear elliptic equations in exterior domains . . 385

Angel Rafael Larotonda and Ignacio Zalduendo, Spectral sets as Banach

manifolds

J. Martínez-Maurica and C. Pérez García, A new approach to the

Kreı̆n-Milman theorem

Christian Pommerenke, On the boundary continuity of conformal maps . . . 423

M. V. Subba Rao, Some Rogers-Ramanujan type partition theorems

Stephen Edwin Wilson, Bicontactual regular maps .........

Jaap C. S. P. van der Woude, Characterizations of (H)PI extensions

Kichoon Yang, Deformation of submanifolds of real projective space

Subhashis Nag, Errata: "On the holomorphy of maps from a complex to a

real manifold" 